\title{
O trabalho de enfermeiras junto à pais de adolescentes através da atividade grupal
}

\author{
Maria Aparecida Tedeschi Cano ${ }^{1}$ \\ Maria das Graças Carvalho Ferriani ${ }^{1}$ \\ Denize Bouttelet Munari²
}

\begin{abstract}
RESUMO
A implementação de ações educativas junto à adolescentes mostra-se como importante fator de contribuição no desenvolvimento do ser humano nessa fase do processo vital. A enfermagem brasileira parece atenta a essa questão, e vários são os trabalhos desenvolvidos junto a essa clientela. Mais recentemente, encontram-se também experiências voltadas não só para os adolescentes, mas para a sua família. Os autores procuraram através desse trabalho relatar suas experiências na discussão de aspectos da adolescência normal junto à pais de diferentes estratos sociais. Trabalhou-se em duas escolas de primeiro grau (uma pública e outra pri-
\end{abstract}

1. Profa. Dra. do Departamento Materno-Infantil e Saúde Pública - Escola de Enfermagem de Ribeirão Preto da Universidade de São Paulo.

2. Profa. Assistente do Departamento de Enfermagem Psiquiátrica e Ciências Humanas Escola de Enfermagem de Ribeirão Preto da Universidade de São Paulo. 
vada) e em igreja católica a convite das mesmas, com grupos de pais interessados (43 mães e 08 pais). Estabeleceu-se a formação de grupos de 12 a 15 participantes programados para encontrarem-se pelo menos duas vezes por três horas no próprio local onde se requisitou a atividade. Utilizou-se técnicas grupais para mediar esses encontros buscando a sensibilização, a integração e o estímulo da criatividade dos pais.

O resultado desse trabalho possibilitou a apreensão de que, assim como para os adolescentes, a maior preocupação dos pais é em relação a sexualidade. Verificou-se ainda que, independentemente do estrato social, os pais conversam pouco com seus filhos e têm limitações para lidar com a rebeldia do adolescente. Essa experiência mostrou ainda o quanto os pais necessitam de espaço para trocarem idéias sobre seus filhos, apontando que a ação educativa voltada para o adolescente pode ser mais efetiva se os pais tiverem oportunidade de reflexão e troca de experiências sobre a adolescência.

Unitermos: adolescente - pais - grupos.

\section{SUMMARY}

The implementation of actions towards teenagers is an important factor contributing to the development of the human being in the phase of life process. Brazilian nursing seems to be attentive to this issue, and several studies have been carried with this clientele. Lately, experience directed at teenagers as well as their families is also to be found. Through this work, the authors seek to report their experience in the discussion of normal adolescence aspects with parents of different social levels. The work was carried out at two first grade school (one public and the other private) and in a Catolic church, by their request, with groups of interested parents (43 mother and 08 fathers). Groups with 12 to 15 participants were formed and scheduled to meet at least twice for three hours in the same place where the activity was requested. Group techniques were employed to mediate these meetings, aiming at the sensitization, integration and stimulation of parents' creativity.

The result of this work revealed that the greatest concern for the teenagers, as well as for their parents, is sexuality. It was also verified that, no matter social leval the parent have few talks with their children and have limitations in dealing with teenagers rebelliousness. This experience also showed how much parents are in need for places where they could exchange ideas about their children, pointing out that the educational action for teenager can be more effective if parents have the opportunity to reflect and to exchange experiences about adolescence.

Unitherms: teenagers - parents - groups. 


\section{INTRODUÇÃo}

A adolescência nos últimos anos tem sido explorada cientificamente por diferentes áreas do conhecimento que buscam um maior entendimento dessa fase da vida do ser humano, onde os valores e vicissitudes do mundo infantil começam a se conflitar com aqueles do mundo adulto. (4) (6) (9) (10) (13)

Essa etapa, como um processo de crescimento e desenvolvimento, depende de vários fatores que estão em movimento no sentido da transformação do ser humano em direção a sua maturação biológica e sócio-cultural. As características psicológicas desse processo evolutivo são dependentes da cultura e da sociedade onde o adolescente se desenvolve.

Por outro lado, a adolescência se constitui em um período de muitos conflitos, dúvidas e convivência tumultuada com as coisas que vão emergindo no cotidiano do viver a adolescência, essas contradições e divergências caracterizam o adolescente como um ser instável emocional mente, contestador e insatisfeito. (11)

ERICKSON (5), entretanto, aponta que essas características do adolescente são necessárias dentro do movimento do seu desenvolvimento, podendo resultar em um ser mais saudável, mais maduro e preparado para enfrentar a vida adulta.

Todo esse processo, no entanto, não se constitui em um momento solitário e exclusivo das vivências do adolescente, mas é intensamente partilhado no contexto social, principalmente com a família que o acompanhará nas suas crises, mudanças a descobertas.

A esse respeito CADETE (3) coloca que "as mudanças ocorridas nesse período se mesclam, levando o adolescente a uma nova postura diante de si, de seus pais, de seus amigos e do mundo. Isso faz com que cada adolescente seja único, plasmado na sua história de vida a da incessante busca inerente a todo ser humano: o perene vir a ser".

Nesse sentido a crise do adolescente não é somente dele enquanto ser em mudança, mas também vivenciada pelos pais. ABERASTURY (1) comenta que "esse processo da vida cujo estino é o despreendimento definitivo da infância tem sobre os pais uma influência não muito valorizada até hoje". Para essa mesma autora o enfoque da adolescência sera sempre incompleto enquanto "não se levar em conta o outro lado do problema - a ambivalência e a residência dos pais em aceitar o processo de crescimento .

Enquanto enfermeiras trabalhando com adolescentes nos preocupamos com essa temática, pois já há alguns anos, notamos ao desenvolvermos trabalhos educativos com essa clientela que a problemática do relacionamento pais e filhos é uma constante. 
Isto nos levou a fazermos um investimento junto aos pais de adolescentes, buscando um melhor entendimento desses conflitos e de quais seriam os fatores dificultadores desse relacionamento e os pontos de maior dificuldade e conflito, por acreditarmos que esse seja um aspecto a ser considerado no planejamento de trabalhos voltados para essa clientela.

\section{A EXPERIÊNCIA VIVIDA}

Esse trabalho desenvolveu-se na cidade de Ribeirão Preto-SP. Uma igreja católica e duas escolas de primeira grau nos convidaram para "conversar" com os pais sobre a adolescência. O motivo do convite, segundo os dirigentes dessas instituições, era que freqüentemente eles se deparavam com atitudes, comportamentos e dúvidas que os adolescentes traziam para a instituição e que refletiam a dificuldade dos pais em lidar com seus adolescentes em casa. Os convites nos foram endereçados em épocas diferentes do ano, a partir do conhecimento dos dirigentes com relação às nossas atividades no Programa de Saúde Escolar (PROASE); desenvolvido no município de Ribeirão Preto.

Considerando a natureza dessa solicitação e de nossas experiências anteriores com grupos de adolescentes, optamos por planejar um trabalho voltado para a ótica grupal enquanto um recurso que produz um clima bastante rico, que propicia troca de experiências a partir da perspectiva do participante.

Acreditamos com isso no potencial do próprio grupo enquanto uma fonte de elementos para a resolução de problemas comuns e, principalmente, para desmistificar a impressão de que os problemas dos pais com os filhos sejam exclusivos de uma família ou outra.

Utilizamos para isso, algumas técnicas de abordagem grupal; que foram adaptadas por nós de algumas sugestões de FRITZEN (8) e ANDREOLA (2) para o trabalho com grupos.

Em um primeiro momento, trabalhamos no sentido da sensibilização dos pais para a discussão com vistas a uma integração e aquecimento iniciais. Para essa etapa usamos uma apresentação individual e posteriormente uma apresentação em duplas rotativas promovendo uma aproximação do grupo como um todo.

No primeiro dia da atividade, o grupo se apresentava individualmente através da escrita. Cada pessoa colocava em uma tira de papel o motivo do seu interesse pela reunião, essas tiras foram colocadas em bexigas coloridas que após estarem cheias eram jogadas para o ar, onde solicitávamos que os participantes as mantivessem no alto em movimento até que se misturassem. Em seguida pedíamos que cada um pegasse uma bexiga e estourasse, liberando o conteúdo que era lido em voz alta para os demais. 
Em seguida formávamos "duplas rotativas" com o intuito de propiciar um diálogo informal, de troca de idéias sobre a adolescência. A cada dois minutos as duplas eram trocadas e iniciava-se um novo diálogo, e assim sucessivamente até que todos tivessem conversado. Ao final formávamos um grupo maior com todos os participantes para onde estimulávamos a discussão da experiência fazendo uma comparação com aspectos vividos na própria adolescência dos participantes.

$\mathrm{Na}$ segunda reunião, o grupo já estando trabalhando sob um clima de confiança a intimidade, passamos a estimular a discussão de temas que preparamos, os quais eram as principais queixas e dificuldades apresentadas por ocasião da solicitação dessa atividade.

Nesse segundo momento dividimos o grupo em três sub-grupos, para trabalharmos com uma redação coletiva que versava sobre os temas. Cada um trabalhava um tema específico, que era posteriormente apresentado aos demais e aberto para a discussão junto com o grupo todo. Os temas trabalhados foram:

I - Como eu lido com a rebeldia do meu filho adolescente;

II -No meu dia a dia em que momento eu troco afeto e/ou ouço o meu filho adolescente;

III- Como eu lido com a sexualidade do meu filho adolescente.

Cada sub-grupo então, trabalhava com o tema específico desenvolvendo-o coletivamente e ao término do tempo destinado a essa etapa, era feita a proposta de reunirmos o grupo todo.

Nessa fase então, os resultados obtidos da redação eram expostos a todos os elementos do grupo a estimulada a discussão de acordo com a vivência, realidade e visão de mundo dos participantes.

A nossa tarefa enquanto coordenadores dessa atividade, era trabalhar com os elementos trazidos pelos pais, evitando julgamentos ou conselhos, mas sim mostrando que a existência dos problemas a dificuldades não era de exclusividade de ninguém em particular, mas que era compartilhado com os demais, já que as questões colocadas eram comuns a grande parte dos participantes.

Por outro lado, as possibilidades de soluções dos problemas que emergiam das discussões deveriam emergir também do próprio grupom sendo o nosso papel, o esclarecimento de dúvidas relacionadas aos aspectos do desenvolvimento fisiológico, psicológico e social do adolescente, e a manutenção do grupo para a tarefa proposta.

Ao final da discussão procurávamos fazer uma avaliação da atividade, destacando a oportunidade de reflexão, de revisão de situações passadas pelos pais com seus filhos, entre os próprios pais, da família como um todo, e sobretudo da importância do diálogo e discussão como uma maneira de compreendermos melhor os aspectos que envolvem o desenvolvimento do ser humano. 


\section{RESULTADOS E DISCUSSÃO}

Verificamos que os 51 pais que participaram desses grupos pertenciam a diferentes estratos sociais; 27 deles tinha um nível universitário, 06 haviam completado o segundo grau, 09 tinha o primeiro grau completo e outros 09 tinham o primeiro grau incompleto. Quanto a atividade que exerciam: médicos (03), professores (12); dona de cada (22); administradores de empresa (03); comerciantes (3); motorista (01); pedreiro (01); advogado (01); psicólogo (O1); dentista (O1); terapeuta ocupacional (O1); agente de turismo $(\mathrm{O} 1)$.

A idade variou de 30 a 60 anos, sendo que 29 estavam na faixa etária de 30-40 anos, 17 na faixa de 41-50 a 05 entre 51-60 anos.

O motivo alegado por 30 pais para participar dos grupos, segundo as anotações na tira de papel foi "para aprender a lidar ou entender $o$ adolescente", os demais 21 pais procuraram o grupo, pois preocupavam-se em "como conversar com os adolescente"; "o que é a adolescência"; "como lidar com a rebeldia do adolescente"; "como conversas sobre namoro e sexo "; "o problema das drogas"; "os amigos do adolescente".

Essas questões estão entre as preocupações dos pais, independente de seu grau de escolaridade ou nível sócio-econômico. Segundo SUPLICY (12) que trata especificamente de questões ligadas à sexualidade, ... "antigamente os pais não tinham muitos problemas em saber o certo ou errado, o que deviam permitir ou condenar; os valores eram absolutos. Hoje, é difícil haver um consenso sobre um sistema de valores... “

A técnica das "duplas rotativas" foi, segundo a avaliação dos pais, muito importante para que eles percebessem que não são os únicos que enfrentam dificuldades para "lidar com o filho adolescente", que outros pais passam pela mesma situação. A frase de um dos pais marca bem essa percepção: "Antes de vir aqui, eu me sentia no mato sem cachorro, hoje eu vejo que somos muitos no mato...

Essa técnica ainda possibilitou aos pais a discussão da "importância do diálogo". A cronometragem do tempo permitiu que eles percebessem que é possível trocar informações e bater papo em 2 minutos.

A recordação da própria adolescência trouxe lembranças e sentimentos que muitos já não a lembram mais: o primeiro namoro, o cigarro, as roupas, a rebeldia, entre outros.

A técnica da redação coletiva possibilitou aos pais maior discussão com relação ao tema proposto e utilização da própria realidade como meio de aprendizagem. 
$1^{\circ}$ Tema - Com relação ao tema: "No meu dia-a-dia em que momento troco afeto ou ouço meu filho", verificamos que de uma maneira geral os pais tem seu tempo limitado para conversar com os filhos em função de inúmeras atividades:

"Não tenho tempo para fazer o que gostaria, pois meu dia-a-dia é muito corrido";

"Tenho refletido que o tempo que reservo para os meus filhos é muito pequeno, a maior parte do dia dedico ao meu trabalho".

Por outro lado, encontramos várias sugestões para tentar resolver a questão:

"Dar atenção quando eles nos procuram com alguma ansiedade ou dúvida, procurar ouví-los";

"Na hora do almoço ou jantar quando temos mais tempo, escutar o que eles têm para contar. fazer desse horário um momento agradável";

"Na hora de ir dormir"; "Durante um passeo ".

Essas questões foram debatidas e todos concordaram com a necessidade de ouvir os filhos, falar um pouco de si mesmo, de suas vidas, infância, juventude.

Em reportagem da Folha de São Paulo (7), sobre uma pesquisa realizada no município de Ribeirão Preto e algumas cidades da região sobre o diálogo entre pais e filhos adolescentes a respeito de homossexualismo, AIDS e drogas, constatou-se que há incoerências entre a resposta dos pais entrevistados que dizem conversas sobre esses assuntos com os filhos e a dos filhos que referem não ter esse tipo de diálogo com os pais. Estes são alguns trechos da reportagem:

"Falar sobre o sexo, drogas, homossexualismo, AIDS entre amigos não é problema, mas contar para os pais já não é característica dos meninos e meninas entrevistados- “

"Os pais têm que se colocar no lugar dos fillos e vice-versa".

"Dizer que vai sentar para conversar e a conversa passa a ser um monólogo nem sempre leva a uma evolução do relacionamento”...

$2^{\circ}$ Tema - Com relação ao tema: "Como eu lido com a sexualidade do meu filho adolescente" foi um dos mais polêmicos e de uma maneira geral, o que eles têm mais dificuldades em abordar.

"Acho minto difícil,falar sobre sexo com ele, talvez porque não tive esse assunto com meus pais ......”; 
"Não sei como poderia conversar com eles sem parecer que estou me intrometendo em suas vidas, pois sexo é a particularidade que eles mais velam "...;

"Noto que ela se fecha quando tento falar sobre sexo"...;

"Em casa a conversa é aberta, franca, mas sobre sexualidade não há o aprofundannento”...

Segundo SUPLICY (12), "a visão da sexualidade mudou muito rapidamente nas últimas décadas. Essa mudança deixou os pais meio perdidos, porque eles vêm de uma geração onde tudo era proibido e agora deparam com uma liberdade que não entendem e que desperta muito medo".

Para ABERASTURY (1), não só o adolescente padece ao longo do período de "crise da adolescência", mas também os pais têm dificuldades para aceitar o crescimento dos filhos e experimentam um sentimento de rejeição frente à genitalidade e à livre manifestação da personalidade que surge dela. "Esta incompreensão e rejeição se encontram muitas vezes, mascaradas debaixo da concessão de uma excessiva liberdade que o adolescente vive, como abandono, e que o e, na realidade".

Mas os grupos chegaram a alguns pontos que consideramos que precisam ser abordados quando se fala em sexualidade:

"Falar e mostrar que cremos em Deus e somos co-criadores e responsáveis pela vida... “;

"Dar oportunidade para que os filhos se manifestem, digam o que pensam... “

$3^{\circ}$ Tema - Com relação ao terra: "Como eu lido com a rebeldia do meu filho adolescente”, os pais, em suas redação, várias vezes se colocaram como pessoas bravas, enérgicas e exigentes. Colocam também que:

"Os filhos acham que sempre têm razão", quando então aumenta a área de atritos. Outra questão que aparece:

"O pai passa para a mãe e vice-versa, a resolução de algum problema e não se chega a um acordo". Mas aparece também que: "O conflito entre paes e,filhos decorre da diferença de valores, os pais querem preservar aqueles que consideram importantes".

Como solução para essas questões sugerem a paciência e o saber ouvir assim como ter algumas regras básicas como horários para sair e chegar, dias da semana para passear e estudar e elogiar o filho quando ele faz alguma coisa positiva. 


\section{CONSIDERAÇÕES FINAIS}

Pensamos que ao oferecer aos pais um espaço para a discussão das questões da adolescência normal, com as quais eles têm dificuldade para lidar no dia-a-dia, facilitamos seu relacionamento com filhos ou propiciamos a oportunidade para que comecem a refletir sobre suas atitudes frente aos filhos adolescente que precisam de ajuda e apoio com uma grande dose de compreensão e afeto. A família tem a responsabilidade de preparar o jovem para a vida adulta transmitindo-lhes o seu padrão cultural. Pensamos que grupos educativos com pais facilitem essa tarefa.

\section{REFERÊNCIAS BIBLIOGRÁFICAS}

1. ABERASTURY, A.; KNOBEL, M.: Adolescência Normal, 9ª ed., Porto Alegre, Artes Médicas, 1991.

2. ANDREOLA, B. A.: Dinâmica de Grupo: jogo da vida e didática do futuro, $2^{a}$ ed., Petrópolis, Vozes, 1983.

3. CADETE, M. M. M.: Da Adolescência ao Processo de Adolescer, Ribeirão Preto, 1994. Tese (doutorado), Escola de Enfermagem de Ribeirão Preto, Universidade de São Paulo.

4. DIMENTEIN, G. Meninas da Noite, $5^{a}$ ed., São Paulo, Ed. Ática, 1992.

5. ERICKSON, E. H. Identidade, Juventude e Crise, Rio de Janeiro, Ed. Zahar, 1972.

6. FERRIANI, M. G. C.; CANO, M. A. T.; SILVA, M. A. I.; UBEDA, E. M. L.: Opinião de escolares adolescente sobre a realização de grupos de discussão, Rev. Bras. Sexualidade Humana, v. 5, nº 2, jul./dez., 1994.

7. Folha de S. Paulo: Homossexualismo é tabu da família, Folha Nordeste SP, 17 out. 1993, p. 10-1, 10-5, 10-6.

8. FRITZEN, S. J.: Exercícios Práticos de Dinâmica de Grupo e de Relações Humanas, $6^{\mathrm{a}}$ ed., Petrópolis, Vozes, 1976.

9. LOLIO, C. A. et al: Mortalidade de Adolescentes no Brasil: 1977, 1980, 1985 - Magnitude e tendências, Rev. Saúde Pública, São Paulo, v. 24, n 6, p. 481-9, 1990.

10. MARCONDES, E.; COLLI, A. S.; SETIAN, N. (coord.): Adolescência, São Paulo, Sarvier, 1979.

11. OSÓRIO, L. C.: Adolescente hoje, Porto Alegre, Artes Médica, 1991.

12. SUPLICY, M.: Conversando sobre Sexo, $17^{\mathrm{a}}$ ed., Rio de Janeiro. Vozes, 1991.

13. VITIELLO, N.: CONCEIÇÃO, I. S. C.: O Exercício da Sexualidade na Adolescência. RBSH, v. Il, n 1, p. 15-24. 1991. 